
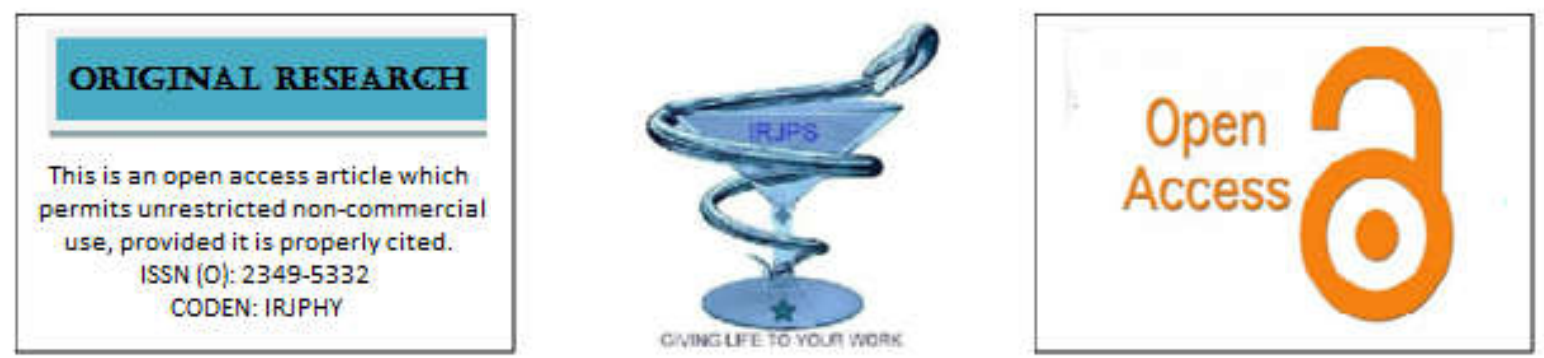

\title{
FORMULATION AND EVALUATION OF IN-SITU GEL FORMING OPHTHALMIC DRUG DELIVERY SYSTEM CONTAINING ATROPINE SULPHATE
}

\section{Eby George*, Chinju M Sivaraman}

Nirmala College of Pharmacy, Muvattupuzha, Kerala, India

\begin{abstract}
In-situ gelling systems are systems which are actually solutions or suspensions and they are capable of undergoing rapid sol to gel transformation by the external stimulas such as $\mathrm{pH}$, temperature etc. The main aim of the present study is to formulate and evaluate the $\mathrm{pH}$ triggered in-situ gel for ophthalmic drug delivery. Atropine is a popularly used drug for mydriatic, cycloplegic, antispasmodic etc. In the present work we have considered the cycloplegic effect of atropine. Due to the rapid wash out and dilution it will de-limits the therapeutic beneficts of drug when used as eyedrops. In the current work we prepared three formulations with different polymers like sodium alginate, carbopol, HPMC, polyacrlyic acid etc. These polymers enhance the viscosity of formulation so that sustained release can be obtained from the formulation. The formulations were evaluated for clarity, $\mathrm{pH}$, gelling ability, compatibility, viscosity etc. This in-situ gel system can be a valuable development for ophthalmic drug delivery when compared with other systems.
\end{abstract}

KEY WORDS: In situ gel, Atropine, carbopol, HPMC, polyacrylic acid, cycloplegia

Corresponding Author: Eby George Email i.d: ebykunnappillil@gmail.com
Indian Research Journal of Pharmacy and Science; 25(2020)2324-2336; Journal Home Page: https://www.irjps.in DOI: 10.21276/irjps.2020.7.2.23 


\section{INTRODUCTION}

Ophthalmic products are specialized dosage forms designed to be instilled into the eye. There are different forms of ophthalmic drug delivery systems like gels, eyedrops, ocular inserts, intra-vitreal injections and implants. The most commonly used ophthalmic dosage forms are solutions, suspensions and ointments. ${ }^{1}$ Ophthalmic drug forms are one of the most important and widely developed area of pharmaceutical technology. The main reason of strong interest of scientists in these drug forms is the problem of a low bioavailability of drug after the application to the eyeball. Low bioavailability is accompanied by the complicated anatomical structure of the eye, small absorptive surface, low transparency of the cornea, lipophilicity of corneal epithelium, etc. As well as the defense mechanisms like tear formation, blinking, and flow of the substance through nasolacrimal duct are also reasons for low bioavailability. $^{2}$

The major limitations in ophthalmic delivery are the reduction of optimum drug concentration at the site of action within the eye. The corneal contact time has been increased to varying degrees by various dosage forms. But, they have not been accepted, because of blurred vision (ointments) or lack of patient complaint (inserts). The eye drops have very poor bioavailability due to their rapid wash out. Most of the systems are applied as solutions or suspensions. So, this can be overcome by modifying the drug as a formulation that undergoes instantaneous in-situ gel formation upon ophthalmic application. They undergo gelation after instillation due to physicochemical changes occurring in the eye. The present work explains the "Formulation and evaluation of in-situ gel forming ophthalmic drug delivery system containing atropine sulphate". In this formulation the in-situ phase transition occurs at the surface of the cornea. At time of instillation dosage form is in solution form and later up on contact with calcium ion present in the lachrymal fluid and surrounding $\mathrm{pH}$ of 7.4 it turns into transparent gel. Thus, the formulation has benefit of both solutions as well as gels. ${ }^{3}$

\section{ESSENTIAL CHARACTERISTICS OF OPHTHALMIC PRODUCTS}

\section{FOREIGN PARTICLES}

All the products should be clear and free from foreign particles, fibers and filaments. And the ophthalmic solutions should be clarified very carefully by passing through bacteria proof filters such as sintered glass filters and membrane filters.

\section{VISCOSITY}

To increase the contact time of drug in the eye, various thickening agents are used such as methyl cellulose, carboxymethylcellulose, polyethylene glycol etc

\section{TONICITY}

These products must be isotonic with lachrymal secretions to avoid discomfort and irritation. The eye can tolerate a range of tonicity from 0.5 to $2 \%$ sodium chloride .The isotonic vehicles used are 1.9\% boric acid, sodium acid phosphate buffer.

$\mathrm{pH}$

The $\mathrm{pH}$ plays an important role in therapeutic activity, solubility, stability and comfort to the patients. Tears have a ph of 7.4. Eye can tolerate solutions having wide range of $\mathrm{pH}$. Alkaloid salts solutions are stable at $\mathrm{Ph} 2$ to 3 but this $\mathrm{pH}$ is irritant to eye.

\section{STERILITY}

The products must be sterile when prepared. Pseudomonas aeruginosa is very common gram negative bacteria which are generally found to be present in ophthalmic products. It may cause serious infection to the eye if sterility is not maintained. So sterility is an important factor to be considered in ophthalmic solutions

\section{SURFACE ACTIVITY}

The vehicles used in ophthalmic preparation must have good wetting ability to penetrate cornea and other tissues. Certain surfactants or wetting agents are added eg: Benzalkonium chloride, polysorbate20, polysorbate 80 , dioctyl sodium. ${ }^{4}$

\section{IN-SITU GELLING SYSTEM}

In-situ gelling systems exist as liquid in room temperature but undergo gelation on coming in contact with body fluids or when there is a change in $\mathrm{pH}$ occurs. In contrast to very strong gels, this can be easily applied in liquid form to the site of action then they swell to make a robust gel that's capable of prolonging the duration of the active substance. Both natural and synthetic polymers can be used for the production of in situ gels. In situ gel formation occurs due to different stimuli like $\mathrm{pH}$ change, temperature 
modulation and ionic cross- linking. So, in situ gels are administered by oral, ocular, rectal, vaginal, injectable and intra- peritoneal routes. The primary purpose of ophthalmic drug forms is to achieve the specified drug concentration in the site of absorption and sustain the drug release which gradually contributes to smaller frequency of application. One of the modifications to conventional forms of ophthalmic drugs was introducing polymers to formulation, which promoted the longer contact time of active ingredient at the corneal surface, thus increasing its bioavailability. Normally the ophthalmic formulations are developed to provide a controlled release of drug to eyeball tissues, include multi compartment carrier systems, inserts, collagen shields, contact lenses, and the so called in situ gels. The advantage of using these new drug forms of controlled release are increase in bioavailability of substance through extending the time of its contact with cornea which can be achieved by effective adhesion to the corneal surface, which ensures the possibility of targeted therapy by preventing the loss of drug to other tissues, ensuring patients comfort when applying the drug forms and during the whole therapy, and increasing resistance to eyes defense mechanisms. ${ }^{5,6}$ The contact time with cornea and bioavailability can be obtained by increasing the viscosity of formulation. Viscosity can be enhanced by hydrophilic polymers of high molecular weight which do not diffuse through biological membranes and which forms three- dimensional networks in the water. Examples of such polymers include polyvinyl alcohol, poloxames, carbomer, polysaccharides, cellulose derivatives, gellan gum, and xanthan gum. The studies has proved that maximum increase of penetration through the cornea by a solution in the forms of eye drops takes place when the viscosity falls into the range of 15 to $150 \mathrm{mpas}$. Hydrophilic polymers are employed in many ophthalmic products, for increasing viscosity. These forms contain polymers which connect through non covalent bonds with conjunctiva mucin and usually are macromolecular hydrocolloids with many hydrophilic groups (carboxyl, hydroxyl, amide) and are able to from electrostatic connections which enables longer contact with eye surface. Mucoadhesive dosage form is characterized by higher bioavailability when compared with conventional dosage forms. ${ }^{7,8,9}$

\section{Mechanism of formation of in situ gels}

Physical mechanism

- $\quad$ Swelling

Swelling occurs when the gel absorbs water from the surrounding environment and expands in the desired space.

\section{- Diffusion}

It involves the diffusion of solvent from polymer solution into the surrounding environment and further result in solidification of polymer matrix.

\section{- $\quad \mathrm{pH}$ triggered mechanism of gelation}

According to the changes in environmental $\mathrm{pH}$ all the $\mathrm{pH}$-sensitive polymers which contain acidic or basic groups either accept or donate protons. The polymers with a large number of ionizable groups are known as poly electrolytes. Swelling of hydrogel increases when the external $\mathrm{pH}$ increases in the case of weakly acidic groups, but swelling decreases if polymer contains weakly basic groups. The most of anionic $\mathrm{pH}$-sensitive polymers are based on PAA (Carbopol, carbomer) or its derivative. Drug formulated in liquid solutions have several limitations, including limited bioavailability and easily removed by tear fluid. To minimize these factors and maximize this drug delivery by making a poly (acrylic acid) (PAA) solution, that would be gel at $\mathrm{pH} 7.4$. The low $\mathrm{pH}$ of PAA solution can cause damage to eye surface before it gets neutralized by the lacrimal fluid. This problem was solved by combining PAA with HPMC, a viscosity enhancing polymer, which resulted polymer mixtures that was solid at $\mathrm{pH} 4$ and gel at $\mathrm{pH} 7.4 .^{10}$

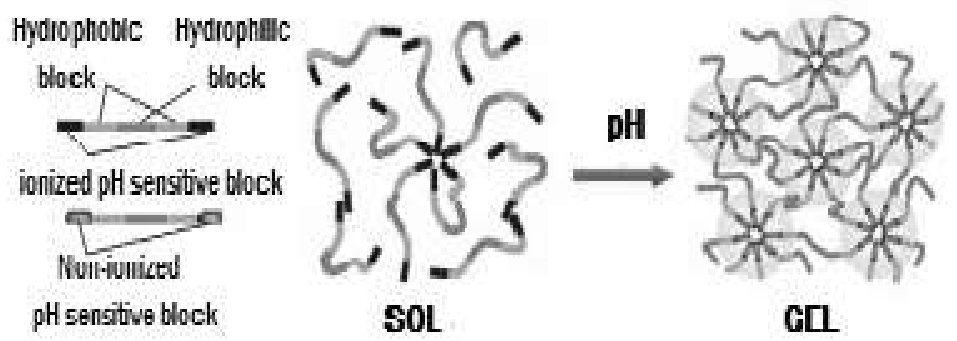

Fig.1: Mechanism of gel formation 


\section{IMPORTANCE OF IN SITU GELLING} SYSTEM

- it is possible to administer accurate and reproducible quantities when compared with already formed gel.

- Ease and reduced frequency of administration.

- Improved patient compliance \& comfort.

- Poor bioavailability exhibited by conventional ophthalmic dosage forms due to rapid precorneal elimination of drug can be overcomed by in-situ gels

- Systems that are instilled as drops into eye \& undergoes a sol-gel transition from instilled dose.

- Liquid dosage forms that can sustain drug release \& remain in contact with cornea of eye for extended period of time is more acceptable.

- Reduced systemic absorption of drug drained through the nasolacrimal duct may result in some undesirable side effects.

- Improved patient compliance.

\section{IDEAL CHARACTERISTICS OF POLYMERS FOR PREPARATION OF IN SITU GEL}

- It should be compatible.

- It is capable of adhering to the mucus membrane.

- Preferred pseudo plastic behavior of polymer.

- Good tolerance and optical clarity is preferred.

- It should influence the tear behavior.

- The polymer should be capable of decreasing the viscosity with increasing share rate ${ }^{11}$

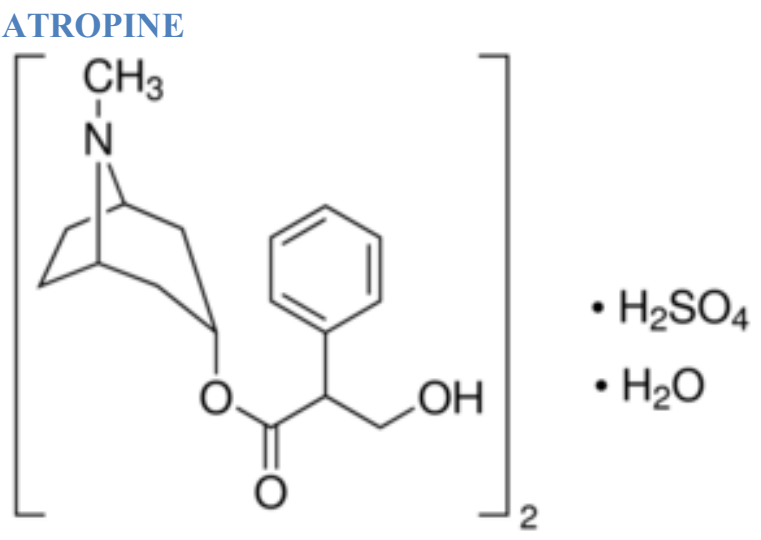

\section{Pharmacokinetic data}

Bioavailability $: 25 \%$

Metabolism $:>50 \%$ hydrolyzed to atropine and tropic acid

Onset of action $\quad: 1$ minute

Biological half-life $\quad: 2$ hours

Duration of action : 30 to $60 \mathrm{~min}$

Excretion

: 15-50\%excreted unchanged in

urine

Atropine sulphate is the sulphate salt of plant Atropa belladonna. Atropine functions as a sympathetic competitive antagonist of muscarinic cholinergic receptors, thereby abolishing the effects of parasympathetic stimulation. This agent may induce tachycardia, inhibit secretions, and relax smooth muscle and the ophthalmic uses of atropine is that when it is topically applied it can be used for cycloplegia to temporarily paralyse the accommodation reflex, and as mydriatic to dilate the pupil. Atropine degrades slowly typically wearing off 7-14 days, so it is generally used as a therapeutic mydriatic. Atropine is used to treat conditions like slow heart rate, to reduce saliva production during surgeries, to treat certain pestide poisonings etc. Normally it is given intravenously or by injection into a muscle. Common side effects are dry mouth, large pupils, urinary retention, constipation, and fast heart rate. It should generally not used in people with angle closure glaucoma. While there is no evidence that its use during pregnancy causes birth defects, it has not been well studied. It is likely safe during breastfeeding. Atropine causes the relaxation of eye 
muscles. This dilates your pupil so that it will not respond to light. Atropine ophthalmic is used to dilate pupil when you have an inflammatory condition or in post surgery situations in which this effect may be useful.

\section{Cycloplegia}

Cycloplegia is paralysis of ciliary muscles of the eye resulting in a loss of accommodation and dilation of pupil. This can be achieved by instilling cycloplegic agents such as atropine, cyclopentolate into conjunctival sac. Due to the paralysis of ciliary muscle, the curvature of lens can no longer be adjusted to focus the nearby objects. This results in similar problems to that caused by presbyopia, in which lens has lost no longer focus on close by object. Cycloplegic refraction is important in assessing patients with decreased vison or ocular deviation. This condition is associated with reading disabilities, learning difficulties, low intelligence, and slow development of visual perceptual skills in children. Cycloplegic refraction is necessary in children because of their high amplitude of accommodation and inability to give reliable subjective responses. ${ }^{12}$

\section{METHODOLOGY}

List of ingredients used for the preparation of formulation

Table no 1: List of ingredients used for preparation of formulation

\begin{tabular}{|c|l|c|}
\hline SI. no & \multicolumn{1}{|c|}{ Ingredients } & Quantity used \\
\hline 1 & Atropine sulphate & $400 \mathrm{mg}$ \\
\hline 2 & Carbapol934 & $3 \mathrm{~g}$ \\
\hline 3 & HPMC & $15 \mathrm{~g}$ \\
\hline 4 & Sodium alginate & $3 \mathrm{~g}$ \\
\hline 5 & Polyacrylic acid & $3 \mathrm{~g}$ \\
\hline 6 & Sodium chloride & $3 \mathrm{~g}$ \\
\hline 7 & Propylene glycol & $60 \mathrm{ml}$ \\
\hline 8 & Benzalkonium chloride & $0.5 \mathrm{~g}$ \\
\hline 9 & Mannitol & $15 \mathrm{~g}$ \\
\hline
\end{tabular}

List of equipments:

Table no 2: List of equipments used for preparation and formulation

\begin{tabular}{|c|c|}
\hline Sl. no & Instruments \\
\hline 1 & UV spectrometer \\
\hline 2 & Digitalweighing balance \\
\hline 3 & Mechanical stirrer \\
\hline 4 & Digital pH meter \\
\hline 5 & Brookfield viscometer \\
\hline 6 & FTIR \\
\hline
\end{tabular}

\section{Analytical method used in the determination of atropine}

The UV spectrophotometry method was developed for the analysis of drug using UV spectrophotometer

\section{Determination of $\mathrm{K}$ max}

Atropine was dissolved in quantity of water and scanned for maximum absorbance in UV double beam spectrophotometer in the range of 200 to 450 nm using buffer as blank

\section{Standard graph of atropine}

$100 \mathrm{mg}$ atropine was dissolved in $1000 \mathrm{ml}$ of water. Series of solutions with concentration range of $5,10,15,20,25,30,35 \mathrm{ml}$ was prepared. Absorbance of 
each at $\kappa$ max was taken and a calibration curve of concentration $\mathrm{v} / \mathrm{s}$ absorbance was plotted.

METHOD OF PREPARATION OF INSITU GEL

To a half portion of purified water dissolve required amount of drug. To this solution added propylene glycol. Dissolve mannitol, benzalkonium chloride and required quantities of polymers. Make the volume to $100 \mathrm{ml}$ with purified water

Table no: 3 Formulation no: 1 ( Carbapo I+ HPMC)

\begin{tabular}{|c|c|}
\hline Ingredients & Amount \\
\hline Drug (Atropine) & $100 \mathrm{mg}$ \\
\hline Carbapol & $3 \mathrm{gm}$ \\
\hline HPMC & $5 \mathrm{gm}$ \\
\hline Sodium chloride & $0.9 \mathrm{gm}$ \\
\hline Propylene glycol & $20 \mathrm{ml}$ \\
\hline Mannitol & $5 \mathrm{gm}$ \\
\hline Benzalkonium chloride & $0.01 \mathrm{gm}$ \\
\hline Distilled water & Qs to $100 \mathrm{ml}$ \\
\hline
\end{tabular}

Table no: 4 Formulation no: 2 (Sodium alginate)

\begin{tabular}{|c|c|}
\hline Ingredients & Amount \\
\hline Drug (Atropine) & $100 \mathrm{mg}$ \\
\hline Sodium alginate & $3 \mathrm{gm}$ \\
\hline HPMC & $5 \mathrm{gm}$ \\
\hline Propylene glycol & $20 \mathrm{ml}$ \\
\hline Mannitol & $5 \mathrm{~g}$ \\
\hline Benzalkonium chloride & 0.01 \\
\hline Distilled water & Qsto $100 \mathrm{ml}$ \\
\hline
\end{tabular}

Table no: 5 Formulation no: 3 (Polyacrylic acid)

\begin{tabular}{|c|c|}
\hline Ingredients & Amount \\
\hline Drug (Atropine) & $100 \mathrm{mg}$ \\
\hline Poly acrylic acid & $3 \mathrm{~g}$ \\
\hline HPMC & $5 \mathrm{~g}$ \\
\hline Sodium chloride & $0.9 \mathrm{~g}$ \\
\hline Propylene glycol & $20 \mathrm{ml}$ \\
\hline Mannitol & $5 \mathrm{~g}$ \\
\hline Benzalkonium chloride & $0.01 \mathrm{~g}$ \\
\hline
\end{tabular}

\section{EVALUATION STUDIES ${ }^{13,14,15}$}

\section{Preformulation study}

\section{FTIR STUDIES}

FTIR studies studies are carried out to check the Compatibility of different polymers with the drug.

\section{CLARITY}

The clarity of the formulations before and after gelling was determined by visual examination of the formulations under light alternatively against white and black backgrounds. 


\section{PH}

The $\mathrm{pH}$ of each of prepared ophthalmic formulations was determined by using Digital $\mathrm{pH}$ meter and electrode. The $\mathrm{pH}$ meter was calibrated before each use with standard buffer solutions. $\mathrm{pH}$ for each formulation was noted and the constant value was recorded.

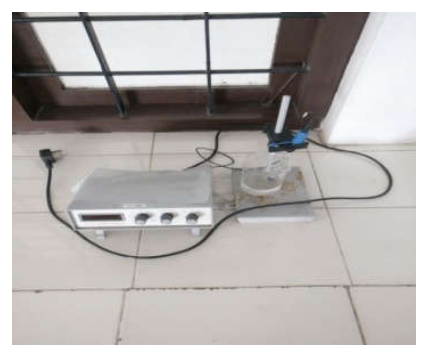

Fig no: 2 Digital pH meter

\section{DETERMINATION OF VISCOSITY OF OPHTHALMIC FORMULATIONS}

The viscosity values were estimated for all the preparations using Brookfield's viscometer.

Procedure for determination of viscosity using Brookfield's viscometer

Instrument was cleaned. Spindle number was adjusted to 64 and rpm was also adjusted according to the formulations. Then the formulation is transferred to a clean beaker and the spindle was dipped to half its contents in beaker. Stable reading for each formulation was noted.

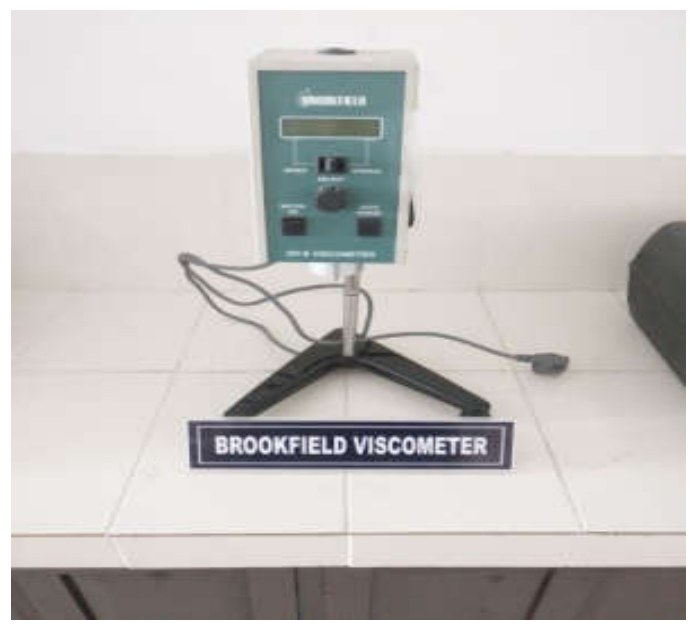

Fig no: 3 Brookfield Viscometer

\section{ISOTONICITY}

Isotonicity is the important characteristics of ophthalmic dosage forms. it should be maintained to prevent the irritation of eye or reduce the tissue damage. Formulations are mixed with few drops of blood and observed under microscope at $45 \mathrm{X}$ magnification and observe the shape of RBC.

\section{TEST FOR GELLING ABILITY}

The individual ophthalmic formulations were added into $2 \mathrm{ml}$ of Stimulated tear fluid $(\mathrm{Ph} \mathrm{7.4)}$ contained in glass vials. The transition of solution to viscous gel was observed visually.

\section{AMOUNT OF DRUG CONTENT}

$1 \mathrm{ml}$ of the eye drop was dissolved in $100 \mathrm{ml}$ water shake well filter the solution the drug content is measured spectrometrically.

\section{RESULTS AND DISCUSSION}

\section{Analytical method used in the determination of atropine}

\section{Determination of $\mathrm{K} \max$}

The $\Lambda$ max of drug was found to be $253 \mathrm{~nm}$

\section{Standard graph of atropine}

Preparation of stock solution

$100 \mathrm{mg}$ atropine was dissolved in $1000 \mathrm{ml}$ water and this is taken as the stock solution.

\section{Preparation of sample solution}

Series of dilutions with the concentration range of $5,10,15,20,25,30,35 \mu \mathrm{g} / \mathrm{ml}$ where prepared by pipetting $5,10,15,20,25,30,35 \mathrm{ml}$ and diluted to $100 \mathrm{ml}$ with distilled water. Calibration curve was prepared using absorption maxima method. The result is shown in the table. 
Table no.6: Spectrophotometric data for the estimation of atropine

\begin{tabular}{|c|c|}
\hline Concentration $\boldsymbol{\mu g} / \mathbf{m l}$ & Absorbance \\
\hline 5 & 0.001 \\
\hline 10 & 0.002 \\
\hline 15 & 0.003 \\
\hline 20 & 0.005 \\
\hline 25 & 0.007 \\
\hline 30 & 0.009 \\
\hline 35 & 0.010 \\
\hline
\end{tabular}

\section{Standard graph of atropine}

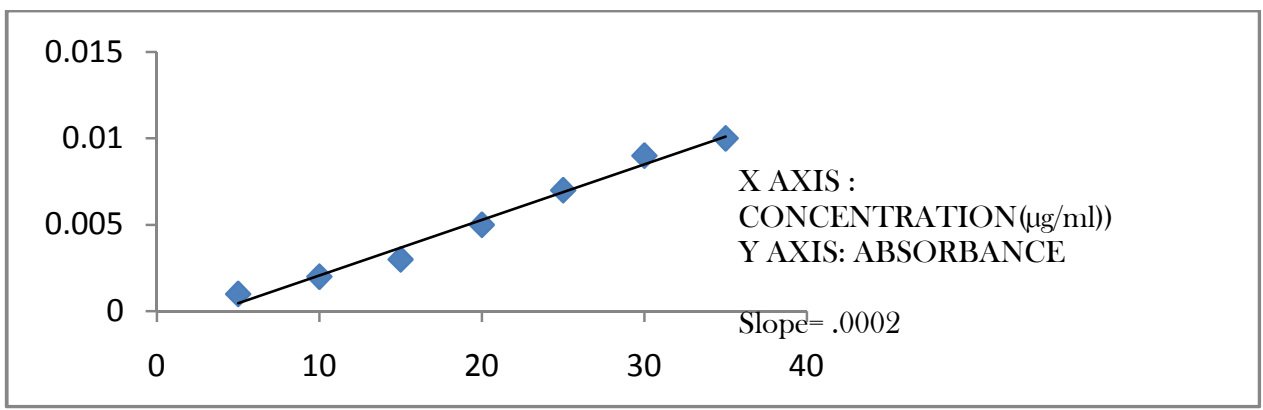

Fig. 4: Standard graph of Atropine

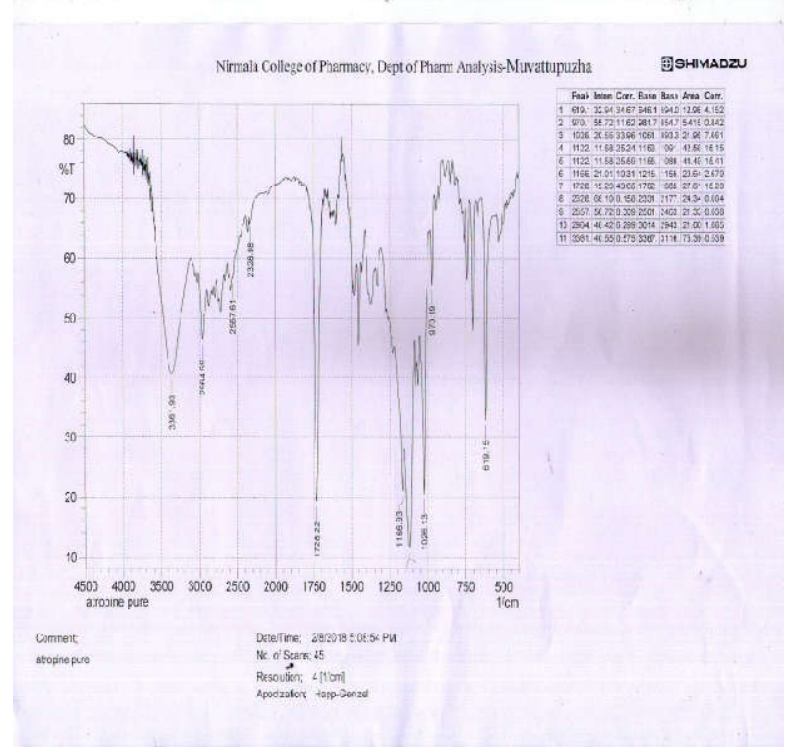

Fig no: 5 -IR Spectrum of Pure Atropine 


\section{FTIR}

As described in the methodology section infra red spectroscopy studies was carried out for pure drug (atropine) and for atropine polymer mixtures. The results are summarized in the figures. There were no changes in the major peaks of atropine in presence of polymers. This revealed that the drug and polymer are compatible with each other.

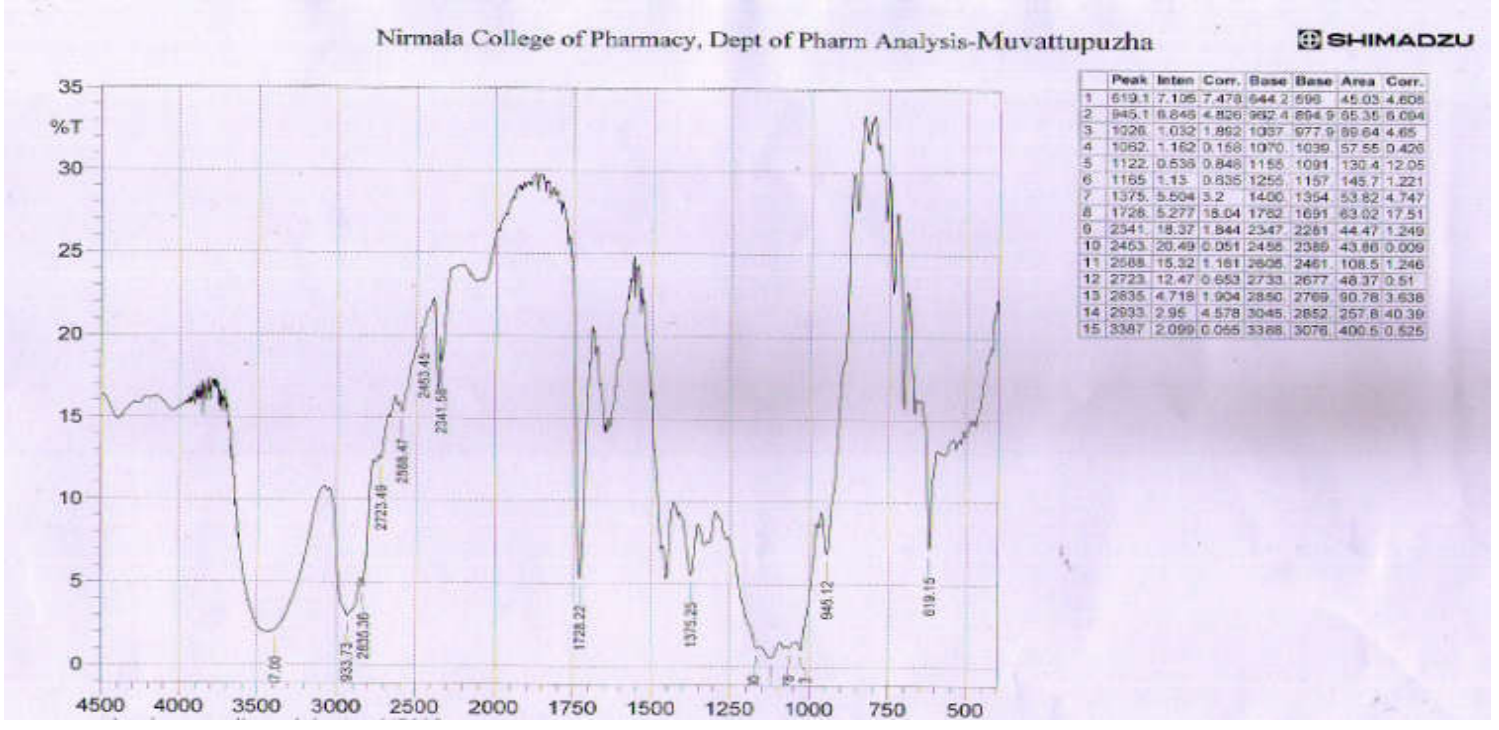

Fig no: 6 - IR Spectrum of Carbapol+HPMC

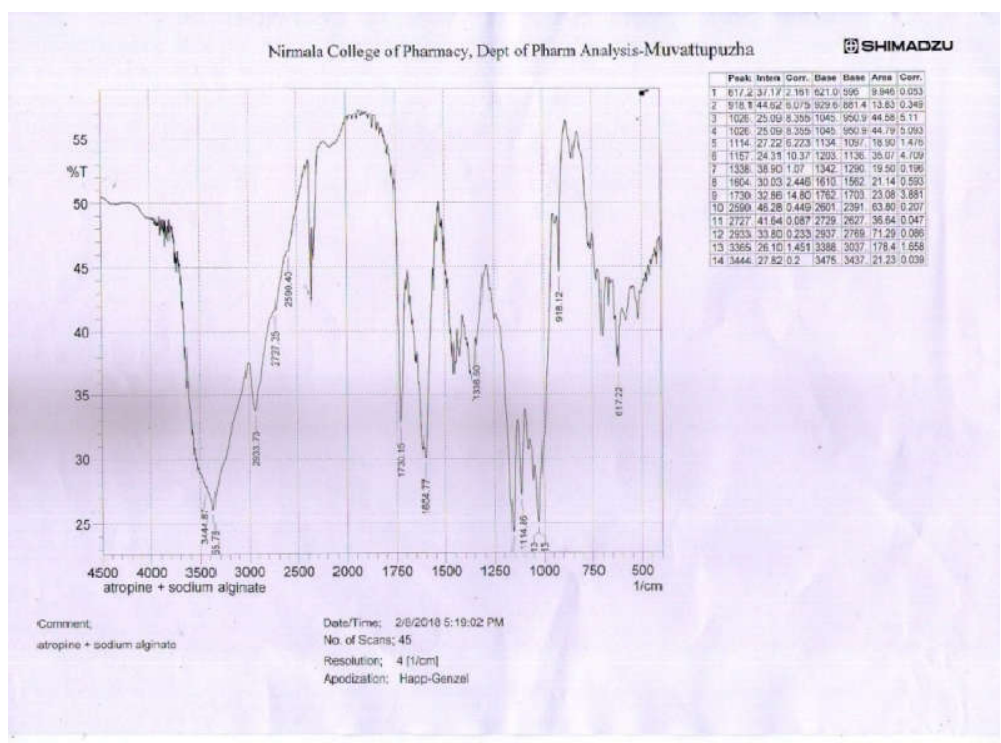

Fig no: 7- IR spectrum of Atropine + Sodium alginate 


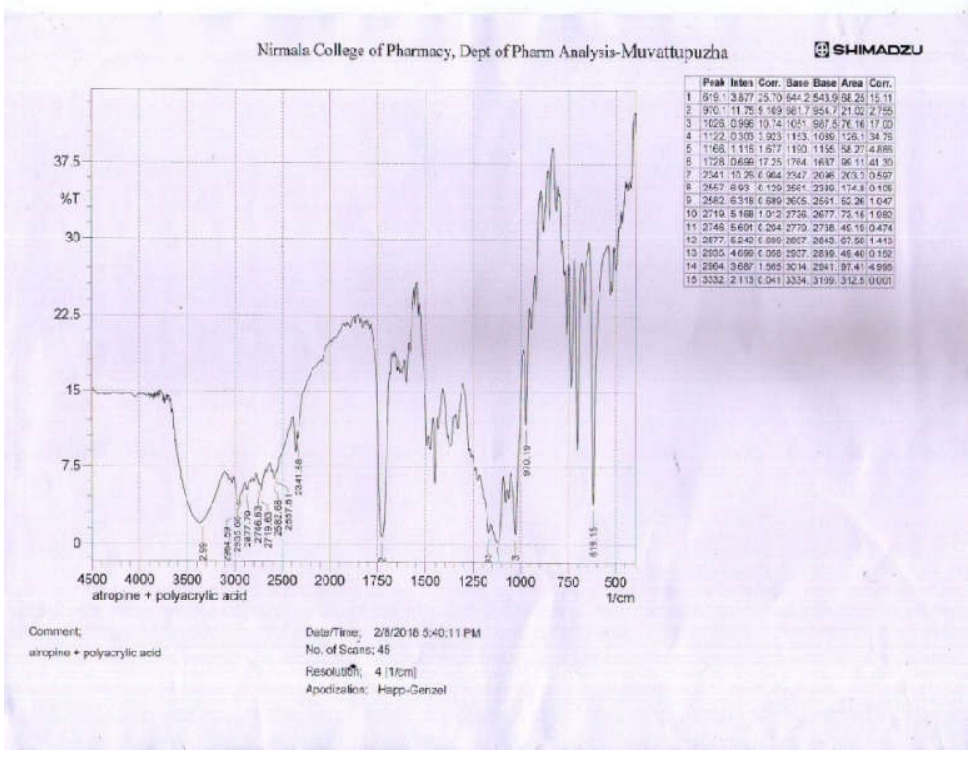

Fig no: 8- IR Spectrum of Atropine +Polyacrylic acid

PHYSICAL APPEARANCE

Table no: 7 Data of physical appearance

\begin{tabular}{|c|c|c|}
\hline Formulation & Clarity & Colour \\
\hline F1 & Excellent & Colourless \\
\hline F2 & Satisfactory & Off white \\
\hline F3 & Good & Light yellow \\
\hline
\end{tabular}

MEASURMENT OF PH
The $\mathrm{pH}$ of the formulations range between $4-7$ which lies in the normal $\mathrm{pH}$ range of eye and would not produce any irritation

Table no. 8 -Data for Measurement of $\mathrm{pH}$ (All values are average of 3 readings)

\begin{tabular}{|c|c|}
\hline Formulation & Ph \\
\hline F1 & 6.8 \\
\hline F2 & 5.8 \\
\hline F3 & 4.7 \\
\hline
\end{tabular}




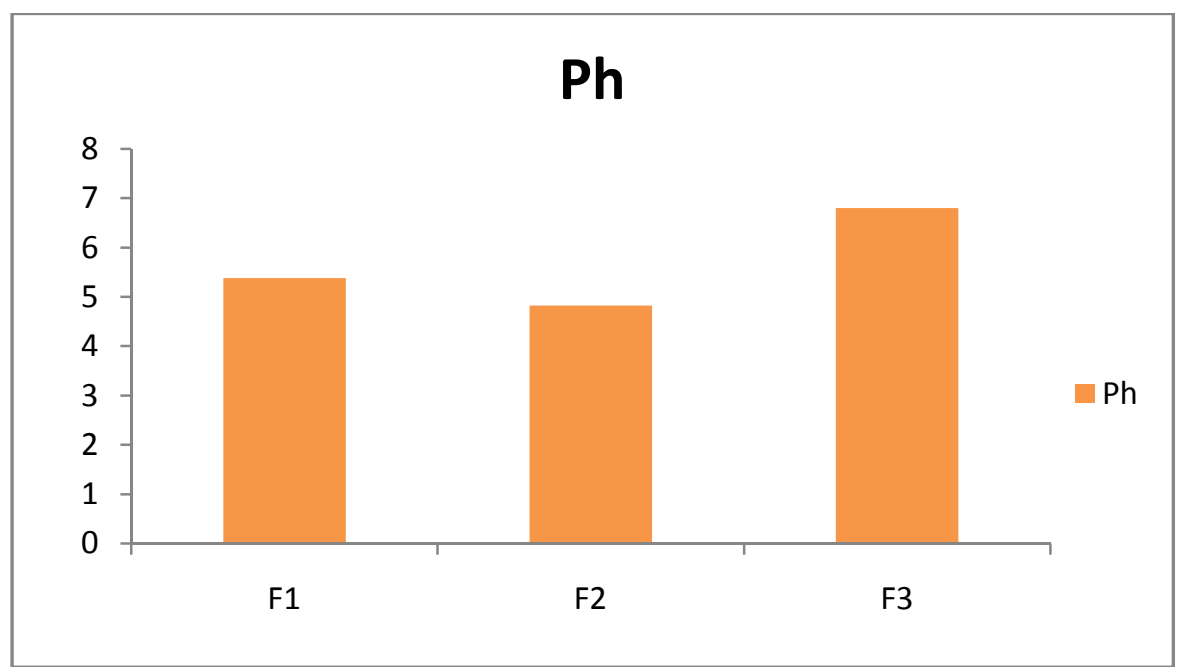

Fig. no:9 Data distrubution of Ph

\section{MEASUREMENT OF VISCOSITY}

The viscosity of in situ gels was found to be different with different polymers

Table no. 9 Measurement of viscosity

\begin{tabular}{|c|c|c|c|}
\hline Formulation & Spindle no & RPM & Viscosity(centipose) \\
\hline F1 & 64 & 60 & 50 \\
\hline F2 & 64 & 20 & \\
\hline F3 & 64 & - & \\
\hline
\end{tabular}

\section{ISOTONICITY}

Isotonicity studies were carried out and it was found that there was no shrinkage or enlargement of cells. This shows that the formulations are isotonic in nature. On mixing the blood with hypertonic solution it was found that the cells was collapsed. And on mixing the blood with hypotonic solution the cells were swollen.

\section{TEST FOR GELLING ABILITY}

Gelling ability studies was carried out and it was found that the three formulations (carbapol, polyacrylic acid, sodium alginate) formed gels insitu when they came in contact with artificial tear fluid having the $\mathrm{pH} 7.4$ 
Table no. 10 Data of gelling time (All values are average of 3 readings)

\begin{tabular}{|c|c|c|}
\hline SI no & Formulations & Time taken \\
\hline 1 & F1 & $2 \mathrm{~s}$ \\
\hline 2 & F2 & $4 \mathrm{~s}$ \\
\hline 3 & F3 & $5 \mathrm{~s}$ \\
\hline
\end{tabular}

\section{MEASUREMENT OF DRUG CONTENT}

Table no. 11 Percentage drug content (All values are average of 3 readings)

\begin{tabular}{|c|c|}
\hline Formulation & \% drug content \\
\hline F1 & 89 \\
\hline F2 & 83 \\
\hline F3 & 86 \\
\hline
\end{tabular}

\section{DISCUSSION}

From the results obtained we can infer that, FTIR studies showed that there is no specific interaction between the drug and the polymers. The $\mathrm{pH}$ of the formulation range between 5-7 which lies in the slightly acidic to neutral range, which is suitable for the eye and would not produce any eye irritations. All the formulations have desired viscocity that enables its easy application into the eye. The perc entage drug content of the formulations was determined and showed comparatively good percentage of drug content. This Indicates the homogenous distribution of drug throughout the formulation.

The best formulation out of the three preparation was F1 (carbapol) and it is selected as the best formulation because it forms clear, colorless, transparent solution. $\mathrm{PH}$ of the formulation is 6.8 which lies in the slightly acidic range and it is capable of gelation on coming in contact with alkaline range. This $\mathrm{pH}$ is good enough so that it donot produce any irritation to the eye. The viscosity lies in the range of 50 centipoise which makes the solutiob viscous enough to instill into the eye. Fast gelling ability of carbapol solution makes it the best formulation.

The above results confirms the feasibility of using carbapol containing insitu gel because it is more effective and safe as compared with other formulations.

\section{CONCLUSION}

The present study deals with formulation and evaluation of insitu ophthalmic drug delivery system, containing atropine sulphate for cycloplegia and to conduct the comparison studies of different polymers. The normal eye drops have very poor bioavailability due to its rapid washout from the eye. So these problems can be overcomed by modifying the drug as in-situ gel forming ophthalmic solutions. Various studies were carried out to determine the clarity, $\mathrm{pH}$, gelling ability, viscosity, compactability etc. the results says that insitu gelling system with atropine can be developed for ophthalmic disorder like cyclopegia. Studies can be more elaborated to make it into a marketed product.

\section{ACKNOWLEDGEMENTS}

The Author express deep gratitude towards Mr. Eby George Assistant Professor, Nirmala college of pharmacy, Muvattupuzha, Kerala for their support to prepare this review article for the completion of pharmacy Master's degree .

\section{REFERENCES}

1. Dr. Shyamala Bhaskaran. Ophthalmic preparations.Pharmaceutical Dosage Forms. Birla Publications (P)Ltd; 2010: 173

2. Baranowski P, Karolewicz B, Gajda M, Pluta J. Ophthalmic drug dosage forms: characterisation and research methods. The Scientific World Journal. 2014 Jan 1;2014.

3. Makwana SB, Patel VA, Parmar SJ. Development and characterization of in-situ gel for ophthalmic formulation containing

Ind Res J Pharm \& Sci|2020: Jun.: 7 (2) 2335 
ciprofloxacin hydrochloride. Results in pharma sciences. 2016 Jan 1;6:1-6.

4. R. M. Mehta. Pharmaceutics 2. Vallavh Prakashal Publications(P)LTD. 2010; 2: 259260

5. Pahuja P, Arora S, Pawar P. Ocular drug delivery system: a reference to natural polymers. Expert Opinion on Drug Delivery. 2012 Jul 1;9(7):83761.

6. Rathore KS, Nema RK. An insight into ophthalmic drug delivery system. Int J Pharm Sci Drug Res. 2009 Apr;1(1):1-5.

7. Gaudana R, Jwala J, Boddu SH, Mitra AK. Recent perspectives in ocular drug delivery. Pharmaceutical research. 2009 May 1;26(5):1197.

8. Rajasekaran A, Kumaran KS, Preetha JP, Karthika K. A comparative review on conventional and advanced ocular drug delivery formulations. International Journal of PharmTech Research. 2010;2(1):668-74.

9. Tangri P, Khurana S. Basics of ocular drug delivery systems. International Journal of Research in Pharmaceutical and Biomedical Sciences. 2011 Oct;2(4):1541-52.
10. Saini R, Saini S, Singh G, Banerjee A, Railmajra DS. In situ gels-a new trends in ophthalmic drug delivery systems. Int $\mathrm{J}$ Pharm Sci Res. 2015;6:386-90.

11. Srividya BJ, Cardoza RM, Amin PD. Sustained ophthalmic delivery of ofloxacin from a $\mathrm{pH}$ triggered in situ gelling system. Journal of controlled release. 2001 Jun 15;73(2-3):205-11.

12. KD Tripathi. Essentials of Medical pharmacology. Jaypee Brothers Medical Publishers (P) Ltd. 2013;7: 115-121.

13. Harish NM, Prabhu P, Charyulu RN, Gulzar MA, Subrahmanyam EV. Formulation and evaluation of in situ gels containing clotrimazole for oral candidiasis. Indian journal of pharmaceutical sciences. 2009 Jul;71(4):421.

14. Preetha JP, Karthika K, Rekha NR, Elshafie K. Formulation and evaluation of in situ ophthalmic gels of Diclofenac sodium. Journal of Chemical and Pharmaceutical Research. 2010;2(3):528-35.

15. Patel JM, Shah KK and Patel MM. formulation and evaluation of temperature dependent ophthalmic gel forming solution of Brimonidine Tartrate. International Journal of Pharmaceutical and Chemical Sciences 2012; 1(4): 1539-1548. 